\title{
HTA Reshaping: Rethinking the Health Technology Assessment Framework in Portugal
}

\author{
João Pereira ${ }^{a}, b, c$ Joana Alves ${ }^{a, b}, c$ Bernardo Rodrigues ${ }^{d}$ Ricardo Caetano $^{e}$ \\ Pedro Brito-Cruz ${ }^{\mathrm{e}}$ Joana Sousa ${ }^{\mathrm{e}}$ Branca Barata $^{\mathrm{d}}$

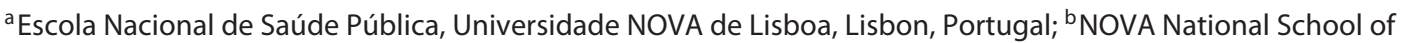 \\ Public Health, Public Health Research Centre, Universidade NOVA de Lisboa, Lisbon, Portugal; ${ }^{\circ}$ Comprehensive \\ Health Research Center (CHRC), Lisbon, Portugal; ${ }^{d}$ Janssen-Cilag Farmacêutica, Porto Salvo, Portugal; eIQVIA, Porto \\ Salvo, Portugal
}

\section{Keywords}

Health technology assessment · Economic evaluation ·

Market access $\cdot$ Innovative medicines $\cdot$ Health financing

\begin{abstract}
Introduction: Health technology assessment (HTA) aims to provide decision makers with relevant data to make informed choices. Recent changes in the Portuguese HTA framework have altered substantially the assessment methodology with regard to economic evaluation, with potential impacts on access and process efficiency. The HTA Reshaping Project had as its main objective informing the debate on HTA in Portugal, thereby identifying improvement opportunities and solutions to the HTA framework that address future challenges. Methods: The project comprised several phases, i.e., (1) mapping and evaluation of different HTA frameworks across Europe, identifying best practices and key variables to consider in future frameworks; (2) conduction of in-depth interviews with relevant stakeholders $(n=$ 11 ); and (3) development of 2 workshops - one with young professionals $(n=12)$ and another with relevant HTA stakeholders $(n=19)$ - to consolidate and further explore vital
\end{abstract}

elements of HTA, aimed at brainstorming ideas and developing solutions to improve some of the most critical points, with a view to addressing future challenges. Results: The comparison of HTA frameworks showed that their purpose and sophistication vary across European countries. For example, the need for economic evidence is not unanimous, and reimbursement agreements vary considerably. Among the stakeholders interviewed there was a high level of agreement on priorities that should be addressed, e.g., expanding and creating national level registries and assuring patient participation throughout the HTA process. The possibility of using managed entry agreements to enhance patients' access, applying multi-indication pricing for medicines with different therapeutic values per indication, and improvement of registry/system interoperability gathered a moderate level of agreement. Conclusions: The Portuguese HTA framework might be further adapted to upcoming challenges and should evolve to improve access to innovative therapies. There is still a long path towards the convergence of HTA frameworks in EU member states.

C 2021 The Author(s). Published by S. Karger AG, Base on behalf of NOVA National School of Public Health karger@karger.com www.karger.com/pjp

Karger $\stackrel{\text { ' }}{5}$

GOPEN ACCESS (c) 2021 The Author(s). Published by S. Karger AG, Basel on behalf of NOVA National School of Public Health

This is an Open Access article licensed under the Creative Commons Attribution-NonCommercial-4.0 International License (CC BY-NC) (http://www.karger.com/Services/OpenAccessLicense), applicable to the online version of the article only. Usage and distribution for commercial purposes requires written permission.
Correspondence to:

João Pereira, jpereira@ensp.unl.pt 
Reformulação da ATS: Repensando o quadro da Avaliação de Tecnologias da Saúde em Portugal

\section{Palavras Chave}

Avaliação de tecnologias da Saúde · Avaliação económica $\cdot$ Acesso ao mercado $\cdot$ Medicamentos inovadores · Financiamento da saúde

\section{Resumo}

Introdução: A avaliação de tecnologias da saúde (ATS) visa facultar aos decisores dados relevantes para a tomada de decisão. As recentes mudanças no quadro português de ATS alteraram substancialmente a metodologia de avaliação económica, com potenciais impactos no acesso e na eficiência dos processos. O Projecto HTA Reshaping teve como principal objetivo informar o debate sobre a ATS em Portugal, identificando oportunidades de melhoria e soluções para o enquadramento futuro da ATS. Métodos: O projeto compreendeu várias fases: (i) Mapeamento e avaliação de diferentes estruturas de ATS na Europa, identificando boas práticas e variáveis-chave a serem consideradas no futuro quadro de ATS em Portugal; (ii) Realização de entrevistas em profundidade com stakeholders ( $n=11)$; (iii) Desenvolvimento de dois workshops, um com jovens profissionais $(n=12)$ e outro com stakeholders ( $n=19$ ), para consolidar e explorar os elementos fundamentais da ATS, com o objetivo de efetuar um brainstorming de ideias e desenvolver soluções futuras para melhoria dos pontos mais críticos. Resultados: A comparação das estruturas de ATS mostrou que seu propósito e sofisticação variam entre países europeus. A necessidade de evidência económica não é unânime e os acordos de financiamento variam consideravelmente. Entre os stakeholders entrevistados, houve um elevado nível de concordância sobre as prioridades, entre elas a expansão e criação de registros a nível nacional e a garantia de participação dos doentes em todo o processo. A possibilidade de usar Managed Entry Agreements para melhorar o acesso dos doentes, aplicando Multi-Indication Pricing para medicamentos com diferente valor terapêutico por indicação e melhoria dos registros / interoperabilidade de sistemas reuniu um nível moderado de concordância. Conclusões: O quadro português de ATS pode ser adaptado aos desafios futuros e deve evoluir para melhorar o acesso a terapêuticas inovadoras. Ainda há um longo caminho para a convergência das estruturas de ATS nos estados-membros da UE.

(c) 2021 The Author(s). Published by S. Karger AG, Basel on behalf of NOVA National School of Public Health

\section{Introduction}

Innovative technologies have the potential to improve population outcomes. However, they are usually more expensive than the existing alternatives $[1,2]$. This is a challenge to health systems around the world, which struggle with finite resources. Therefore, it is important to ensure that new technologies demonstrate value for money, i.e., that the health improvements brought about justify the additional costs. Health technology assessment (HTA) is a systematic process for evaluation of health technologies to inform decision making [3]. HTA intends to inform decision makers about how to allocate resources effectively and efficiently. It is multidisciplinary and rooted in good practices in evaluation, including sound research methods. One of the key elements in HTA is economic evaluation, which aims to assess whether a health technology or intervention provides good value for money for the health service and the community. To evaluate value for money, it is usual to measure the differential in costs required to achieve an extra health benefit of a new therapy. Thus, HTA involves an assessment of the properties, effects, and impacts of the technologies in terms of their efficacy or effectiveness as well as from the point of view of economic efficiency.

Australia was the first country to use these methods, in 1993 , followed by several OECD countries [4, 5]. In several countries HTA is used to define the health coverage of procedures, pharmaceutical products and equipment, and/or clinical guidelines. HTA agencies usually evaluate efficacy, effectiveness, and efficiency, while governments, insurance funds, or other third-party payers decide on whether the technology should be covered. The decision could be total coverage, partial coverage (with patient copayment or restriction to distinct indications/subpopulations) or coverage subject to new evidence development $[4,5]$. At the European level, HTA was traditionally developed within each country [6]. Recently, international networks, such as the EUnetHTA (European Network for Health Technology Assessment), have permitted the promotion of HTA knowledge sharing and the establishment of good practices and guidelines. However, despite the recent transnational collaborations, the purpose, frameworks, and sophistication of the methods used vary across countries [7].

HTA has been undertaken by public bodies in Portugal for over 2 decades. It has been mandatory to determine the coverage of ambulatory drugs since 1999 (decree-law No. 305/98) and for hospital drugs since 2007 
(decree-law No. 195/2006). Portugal became one of the first European countries to develop guidelines for HTA. They were published in 1998 (regulation 19064/99) [8]. These guidelines were defined with pharmaceutical products in mind. However, evolution of HTA methodologies, international collaborations, and opportunities to incorporate real-world evidence along the product life cycle raised additional methodological challenges [9]. Recently, the Portuguese Commission for Health Technology Assessment (CATS) updated the Portuguese guidelines on economic evaluation, making various changes to the HTA methodology [10]. Among these were the procedure for comparator selection, recommending multiple comparisons with all relevant alternatives, and the underlying evaluation perspective to be followed, moving from a stated preference for the societal perspective to one where only costs falling on the NHS are considered. These changes might affect access to new technologies.

The aim of this article is to report on the results of the HTA Reshaping Project. This project aimed to establish a consensus based on expert opinion regarding future challenges in the assessment of pharmaceuticals and access to new therapeutic alternatives (e.g., managed entry agreements [MEA], multi-indication pricing [MIP], assessment of orphan medicines, patient-reported outcomes [PRO], medicine reassessment, etc.), to assess the impact of potential changes to the current HTA process in Portugal, and to identify solutions to and/or improvement opportunities for the HTA framework that would allow the mitigation of current/future challenges.

\section{Methods}

\section{Study Design and Population}

The methodology of the HTA Reshaping Project consisted of several phases: (1) mapping and evaluation of different HTA frameworks, identifying best practices and variables to consider in future frameworks; (2) conduction of in-depth interviews of relevant stakeholders $(n=11)$; (3) development of 2 workshops - one with young professionals $(n=12)$ and another with relevant HTA stakeholders $(n=19)$ - to consolidate and further explore vital elements of HTA, aimed at brainstorming ideas and developing solutions to improve some of the most critical points, while preparing for future challenges. The starting point for the discussion in the workshops was provided by the results from phases (1) and (2). The methods for those phases are further detailed below.

\section{Mapping and Evaluation of Different HTA Frameworks}

A vital step in the early stages of the project was to carry out a literature review to examine the current situation and provide an overview of international best practices regarding HTA. Understanding the HTA landscape at the European level was an essential step to assess the convergence of the Portuguese HTA framework with comparable countries, i.e., other EU member states.

A nonsystematic literature review was performed to evaluate and compare the different HTA frameworks across Europe, followed by identification of the future challenges mentioned in the literature. The review centered on economic aspects of HTA processes, i.e., health economic evaluation methodologies and other associated themes such as pricing mechanisms and contracting. Regarding economic evaluation, a focus was placed on a set of key HTA parameters (comparators, population, therapeutic assessment, time horizon, analytical methods, perspective, costs, PRO, and budget impact analysis).

In order to select comparable jurisdictions for benchmarking with Portugal, 3 sequential criteria were applied, i.e., region, economy/market dimension, and data availability. The regional filter was the first to be applied (i.e., Western Europe - the region to which Portugal belongs). The major economies and markets within this region were selected for analysis. Hence, after assessing data availability for this set of countries, a final group of 7 major European economies (Belgium, France, Germany, Italy, the Netherlands, Spain, and the UK) and other relevant European countries (e.g., Nordic countries - Denmark, Finland, Norway, Sweden; other EU member states, and Switzerland) were selected for comparison with the Portuguese setting.

\section{Interviews}

Several key Portuguese HTA stakeholders were interviewed to gather information on their insights regarding the current framework and its future challenges. In-depth interviews were designed to understand the stakeholders' position concerning the main topics explored during the previous phase. This allowed identification of additional challenges and topics to be tackled in the future. Although in-depth interviews are less structured than other qualitative methods, they allow coverage of topics in great detail [11]. From the universe of topics explored during the interviews, a set of key aspects were selected according to their being mentioned a greater number of times by the interviewees.

With the intention of engaging most organizations and stakeholders that are either related to or have a profound knowledge and experience of Portugal's HTA process, we sent out invitations to institutions asking them to appoint a representative to attend for interview or the later workshop (e.g., Ordem dos Farmacêuticos, APIFARMA, APAH). In some cases, because the experience and interest of stakeholders in the subject is public and recognized, a direct invitation was made (e.g., Academia, INFARMED-CATS, Portuguese Health Economics Association, and patient associations). From these contacts, there emerged a subset of stakeholders that were willing and accepted to participate in one or more activities comprising the research initiative. While this method does not guarantee a fully representative sample of organizations and stakeholders, we strived to achieve a balance of different viewpoints relevant to the HTA landscape.

The initial target was to carry out 10-15 interviews, and 11 people agreed to participate. The group of stakeholders had a diverse composition, with 5 persons being drawn from academia, 2 from the Portuguese Health Economics Association, and 4 from other sectors, such as the Executive Commission of CATS, ISPOR Portugal, and the pharmaceutical industry.
Port J Public Health 2021;39:36-47 DOI: $10.1159 / 000516501$
Pereira/Alves/Rodrigues/Caetano/BritoCruz/Sousa/Barata 
Workshops

The following 2 workshops bringing together various stakeholders were organized with a view to presenting the project's preliminary results and to brainstorm solutions and suggestions for mitigating the most critical HTA future challenges:

- HTA Junior Workshop. On November 12, 2019, a workshop was organized to gather insights from 12 young professionals (the initial target was 10-15 participants). These included members from universities, i.e., PhD students, members from the pharmaceutical industry, consultants, and professionals working in HTA-related projects. The main purpose of this workshop was to gather the point of view of young professionals involved in HTA-related themes who could possibly contribute with fresh and innovative ideas that fall within the project's scope. This workshop was especially relevant since it allowed assessment of the convergence/divergence of thoughts with HTA experts participating in the second workshop regarding the topics addressed in both sessions.

- HTA Reshaping Workshop. On November 20, 2019, a second workshop was organized aimed at gathering insights from key stakeholders within the Portuguese HTA community. Of the initial target of 15-25 participants, 19 people agreed to participate. Stakeholders were selected given their important role in the HTA process in Portugal either presently or in the recent past. This workshop included 6 people from the pharmaceutical industry, 4 from academia, 3 professionals from relevant associations (e.g., APAH, APIFARMA, Ordem dos Farmacêuticos), 3 service providers or research centers (e.g., consultancy and research), 1 from the regulator (INFARMED), 1 from patient associations, and a person from other HTA-related professions. The selection criteria for the expert workshop is described in the previous subsection. Regarding the Junior workshop, participation was based on recommendations from academic stakeholders (e.g., PhD and masters students and young researchers) and on self-registration following information disseminated in faculties.

The discussion among HTA experts in the 2 workshops was intended to consolidate and further explore vital elements of HTA, aimed at brainstorming ideas and developing solutions to improve some of the most critical points, while preparing for future challenges. Thus, the questions addressed in the workshops emerged from the literature review and the in-depth interviews.

The methodological approach used in the workshops is akin to an extended focus group, of which there are various examples in the literature (e.g., Timotijevic and Raats [12]). We chose not to use a Delphi type approach as it involves both qualitative and quantitative elements and because our objective was to get close to the participants' understanding of and perspectives on particular issues rather than generation of generalizable data. Focus groups, in the extended form of a workshop, are helpful in identifying the thinking, perceptions, and impressions of a particular group [13].

Conclusions from the workshops were compiled by 4 authors (B.B., B.R., P.B.-C., and R.C.). These were classified according to the level of agreement as follows: high (accepted by all of the participants), moderate (accepted by some), and low (accepted by only 1 participant).

\section{Results}

\section{Mapping and Evaluation of Different HTA}

Frameworks

The first phase of the project consisted of performing a literature review to evaluate and compare the different HTA frameworks across Europe. Some examples of the distinct features of drug evaluation in European countries are described below.

The purpose and sophistication of HTA frameworks vary across European countries. While most HTA bodies are aligned on the need for clinical evidence, the necessity for economic evidence (particularly the requirements for budget impact and cost-effectiveness data) might differ. In some countries, such as France, budget impact analysis is not mandatory [14]. The HTA processes are also different regarding the choice of comparator. In the UK and the Netherlands, the comparator is the best current alternative or treatment. In France, 3 comparators from the same therapeutic group are required, i.e., the most frequently used, the cheapest, and the most recently added to the positive list [15].

These different HTA practices in EU countries might result in conflicting decisions. A previous study identified a low alignment between HTA processes and recommendations [16]. For new active substances approved by the EMA (2008-2012), only 6 out of 28 pairs of countries' decisions were evaluated as highly congruent (the percentage of congruent recommendations for the total number of medicines reviewed by both jurisdictions was equal to or higher than $75 \%$ ). These were also the countries that have separate agencies or organizations performing the regulatory, HTA and decision-making functions. Although the HTA recommendations were aligned according to the system type, the results were less aligned according to the HTA process type. According to the authors, these discrepancies might also be explained by the quality of evidence used, the level of uncertainty acceptance, and the different methods of assessment or priorities.

Portugal is more aligned with the UK and Nordic and Flemish countries. These countries use cost-effectiveness analysis methods to inform pharmaceutical access. In the $\mathrm{UK}$, the cost-effectiveness threshold is explicitly set at GBP 20,000/QALY to GBP 30,000£/QALY [17], while no other country has an explicit threshold. Nevertheless, agreements on price or volume caps represent an informal way of implementing "affordability thresholds" [18].

Reimbursement agreements vary considerably between countries. In France, reimbursement agreements 
between the state and insurers might be based on results or price-volume agreements and with a sales cap [19]. In the Netherlands, drugs are subject to an approval process and a maximum price is defined for which the medicines are reimbursed [20]. In Belgium, the reimbursement agreements schemes might be based on price-volume, evidence, caps on costs, and portfolio approaches [21]. In Italy, reimbursement assessment is based on clinical and pharmacoeconomic data, itself grounded on an innovation algorithm. Managed entry agreements are the main reimbursement mechanisms, with agreements based on results and costs [22]. In the UK, clinical outcomes and other information are available through a database, and reimbursement agreements are based on results and on a cap based on cost or revenues [23]. The HTA process in Spain is more complex due to decentralization of the health system. The autonomous regions are obliged to include in their reimbursement list any drug in the Nomenclatór and they can add different drugs to each regional list. The reimbursement agreements between the state and insurers might be based on results and pricevolume, 2-tier pricing, and coverage with real-world evidence development [24]. Finally, in Portugal, hospital products are fully covered and regarding pharmacy drugs a percentage of their price is reimbursed depending on the pharmacotherapeutic category, with a special scheme for pensioners and people with chronic diseases. In some cases, an economic assessment with a cost-effectiveness ratio might be required. The reimbursement agreements are based on price-volume, results, discounted prices, and risk-sharing [25].

Countries face a challenge to balance innovation with affordability. Flume et al. [18] describe in detail some approaches in European countries. They report a high variability across countries, each combining several tools adapted to their health system characteristics, such as "affordability thresholds," price-volume agreements or caps on individual product sales, and special budgets for innovative drugs. However, each strategy has its own drawbacks and there is no "one size fits all" approach. For example, innovation specific funds accelerate patient access but often represent a higher level of expenditure.

In order to increase access while simultaneously guaranteeing affordability, different European countries are currently using 3 different strategies of MIP [26]. The Netherlands opted to establish a price for the first indication, which is used to anchor the price of all further indications. If further indications are not cost-effective, either a lower price is negotiated, or the medicine may not be reimbursed. Another possible strategy is use of a weight- ed price across all indications. This is the case of Germany, which negotiates the price for each new indication. Those negotiations are then reflected in a final common price. In France, the individual negotiations for each indication are scored according to the therapeutic benefit and the public price reflects the weighting of the indication per expected volume. Belgium applies price reductions corresponding to one third of the spending increase due to multiple indications divided by the new spending volume. The third approach is setting of a different price for each indication. This is the case of Italy, which uses a large registry with individual patient data. Finally, the UK reviews each indication separately and they are only recommended if they are shown to be cost-effective. Despite the appealing characteristics of MIP, it entails several drawbacks. With the increased access, MIP can ultimately increase expenditures and pose a heavier administrative burden, as it requires detailed information and can increase the risk of arbitrage if the drug is used in the higher-value indication at the lower-value indication's price.

European HTA frameworks do not cover the full scope of gene and cell therapies. These new therapies may cure severe and life-threatening diseases but they may threaten health system sustainability. However, due to small patient populations and the distinct aspects of these therapies it is difficult to produce robust clinical evidence to meet traditional HTA guidelines [27]. European countries might have to consider specific HTA methods to reflect the uncertainty using population level health effects and to consider different payment mechanisms.

Despite international networks recently developed to promote HTA knowledge sharing and the establishment of good practices and guidelines, the purpose, frameworks, and sophistication of the methods used vary across European countries. Countries are heterogeneous and implement different HTA methods, and recommendations for new medicines also differ. Also, they face the emergence of future challenges such as new agreements methods and alternative pricing strategies and reimbursement mechanisms (e.g., MEA and MIP). In this context, it is still unclear whether HTA frameworks across Europe are converging and, particularly, whether Portugal is converging with Europe.

\section{In-Depth Interviews}

Several key Portuguese HTA stakeholders were interviewed to gather information about their insights regarding the existing framework and its future challenges. The interviews were directed at 11 stakeholders, selected due
Port J Public Health 2021;39:36-47 DOI: $10.1159 / 000516501$
Pereira/Alves/Rodrigues/Caetano/BritoCruz/Sousa/Barata 
to their relevant role in the HTA process, in the present or in the recent past. The results from the interviews are detailed in the following paragraphs (see online suppl. Appendix 1 for details about topics covered in the interviews; see www.karger.com/doi/10.1159/000516501 for all online suppl. material).

Pharmacoeconomic Assessment Guidelines. The interviewees recognized that the Portuguese HTA process is based on solid legislation when compared to other European countries. They pointed out that the use of realworld evidence needs to be promoted and supported by adequate databases, such as the Registo Oncológico Nacional (RON) or SI.VIDA.

Most of the interviewees agreed that the societal perspective is more comprehensive than the NHS perspective and thus more beneficial since it broadly captures the entire benefits of drugs for the whole of society. However, it comes with methodological challenges, i.e., with regard to accurate measurement of all of the relevant costs for the appraisal. Since the nature of the included costs reflects the adopted perspective, current guidelines only require the inclusion of direct costs impacting the NHS. The interviewees suggested that other indirect costs (such as transportation, nonmedical costs, or productivity costs) could also be relevant despite being difficult to measure.

The stakeholders referred that pharmacoeconomic models for evaluating drugs are becoming increasingly complex and sophisticated, which does not necessarily mean they are leading to better results. The requirement of more tailor-made models might increase data needs and make the interpretation of results more difficult, i.e., for the general public.

HTA Process for Medical Devices. Creation of a lean HTA process for Medical Devices comprises multiple challenges such as defining clear assessment criteria for distinct types of devices (e.g., prostheses, ophthalmological devices, breast implants, or pacemakers). However, the urgency to implement an HTA process for devices was consensual across the stakeholders. This process needs to be complemented with appropriate information systems and databases.

Patient Participation in the HTA Process. It was unanimous that patients' participation in the HTA process is vital. Patients are crucial for contributing with systematic measurement of outcomes (PRO) for defining which outcomes should be measured and how clinical endpoints should be assessed. Such participation could be assured either through the patient's associations or by individual patient involvement. The added value of such participa-

HTA Reshaping in Portugal tion would be in providing a patient-centered perspective, with insightful perspectives on the main challenges of the treatment and living with the disease, and perceptions of comparison with the standard of care. The way to incorporate them into the process is, however, less clear, according to the stakeholders. PRO may ultimately lead to a challenge on weighting the relative importance of each stakeholder and gathering data for certain groups of patients (e.g., how would these outcomes be measured for children or people with dementia?). To fully explore the potential of PRO, it is crucial to further develop current information systems to include this feature. One interviewee mentioned the potential of pharmacies in gathering data and creating real-time evidence.

Assessing Drugs with Immature Data. Conditional approval of drugs was not consensual among all stakeholders. Approval of drugs based on immature data comprises several challenges, i.e., the trade-off between assuring access and the uncertainty regarding drugs' efficacy and safety. The stakeholders recognized that the generation of real-world evidence might be useful and also raised great concerns regarding potential safety issues arising from decision making based on immature data.

Multi-Indication Pricing. MIP can be a useful mechanism to foster research and development for additional indications. Nevertheless, it could limit a given drug's usage among certain subpopulations and/or increase patient discrimination. Some interviewees perceived MIP as unethical. To minimize this negative effect of price discrimination, proper audits to prescription tracking for drugs using MIP should be performed. Another identified challenge was prescription tracking for different indications given that it is difficult to monitor whether physicians are prescribing a certain drug for the right indication. The stakeholders referred that price discrimination must be supported by adequate registries for each indication.

Assessing Drug Combinations. Currently, drug combinations are assessed as the sum of products, evaluated separately. The assessment of drug combinations might be beneficial since they might incorporate synergies of using both products in combination. A major challenge that may arise from assessing these drug combinations are situations in which 2 different companies are involved.

Drug Reassessments. Drug reassessment is one of the major topics requiring improvement according to most interviewees, being particularly relevant for medical devices and situations where the evidence available during the assessment phase is weak and/or limited. Gathering realworld evidence to support reassessments could represent a significant challenge in terms of workload for institutions, 
Table 1. Topics discussed in the workshops

\begin{tabular}{|c|c|}
\hline HTA Junior Workshop & HTA Reshaping Workshop \\
\hline 1. HTA process in Portugal - from 1998 to 2019: are we converging with & 1. Pharmacoeconomic assessment guidelines \\
\hline Europe? & 2. How can we include patients in the HTA process? \\
\hline 2. Assessing drugs with immature data and drug reassessments & 3. Are we prepared to assess new therapeutic alternatives? \\
\hline 3. Assessing drug combos, cell and gene therapies, and orphan drugs & 4. How can we assess therapies' effectiveness in Portugal? \\
\hline 4. MEA and MIP & $\begin{array}{l}\text { 5. Are we ready for new financial and outcome-based agreements (e.g., MEA } \\
\text { and MIP)? }\end{array}$ \\
\hline
\end{tabular}

such as hospitals. Additionally, another challenge is the identification of which data would need to be collected.

\section{Workshops}

Two workshops were then performed to discuss the main conclusions from the previous phases. The young professionals' workshop aimed to discuss innovative ideas, promote the discussion of some of the most relevant HTA-related challenges, and develop possible solutions. The expert's workshop proposed discussion of the topics that require more expertise, gathering insights from renowned stakeholders within the HTA community. The main topics discussed are presented in Tables 1 and 2.

\section{HTA Junior Workshop}

The workshop gathered 12 young professionals involved in the HTA process in Portugal.

MEA and MIP. These methods might be a relevant mechanism to improve access. However, they should be supported by an improved registry database. Participants identified the possibility of these databases being (partially) funded by the pharmaceutical industry. MIP implementation must be assured by accurate prescription tracking.

HTA Process in Portugal from 1998 to 2019. The change in pharmacoeconomic guidelines from the societal to the NHS perspective provides no incentive to measure indirect costs and those costs that have no impact on the NHS budget. This may exclude some of a drug's added benefit from the analysis. Regarding the comparator, using all available alternatives provides increased flexibility during negotiation processes but can intensify the workload and lead to market access delays.

Regarding patients' participation, it was considered critical to involve patients on the definition of real-world outcomes. However, some challenges emerged from the discussion, such as the moment and methods of participation. Participants also suggested the use of multicriteria decision analysis to reflect the perspective of multiple stakeholders in the pharmacoeconomic assessment.

Assessing Drugs with Immature or Incomplete Data and Drug Reassessments. According to the young professionals, the use of immature or incomplete data to access drugs might result in earlier access to therapies but this comes with great uncertainty. They reported that drug reassessments are essential for several reasons, i.e., they might mitigate the efficacy-effectiveness gap, and they may be used to support value-based pricing and improve NHS budget management. Participants also suggested the validation of surrogate markers.

Assessing Drug Combinations, Cell and Gene Therapies, and Orphan Drugs. Although drug combinations might provide an incremental benefit in comparison with monotherapy, they might be methodologically challenging, i.e., in situations where drugs are from different companies and in cases in which combinations are not costeffective, although single therapies may have been granted reimbursement.

When assessing cell and gene therapies and orphan drugs, young professionals suggested that a higher costeffectiveness threshold be accepted (although with risks for the NHS budget), that multicriteria decision analysis be used, and that early access programs to gather more real-world evidence to support assessments be promoted.

\section{HTA Reshaping Workshop}

The workshop gathered 19 HTA Portuguese experts.

Pharmacoeconomic Assessment Guidelines. The identification of comparators and the evaluation perspective were controversial among the participants. The revision of national pharmacoeconomic guidelines led to some confusion about identification of the relevant comparators and there was some concern about their late communication to pharmaceutical companies. Participants suggested that it is vital to assure that pharmacoeconomic guidelines are clear for the general population. Some sections of the guidelines require more detail, such as "other costs," so that they can be quantified (e.g., copayment 
Table 2. Main topics addressed in the workshops according to the level of agreement

\begin{tabular}{ll}
\hline Suggestions and solutions & Main arguments \\
\hline High level of agreement & \\
\hline $\begin{array}{l}\text { It is crucial to expand registries and create a } \\
\text { national-level registry. }\end{array}$ & $\begin{array}{l}\text { A national-level registry must be created, aggregating all of the data required for } \\
\text { supporting pharmacoeconomic assessments. } \\
\text { Intercommunication between systems and hospital-level registries is } \\
\text { fundamental to allow evidence-based decision-making. }\end{array}$ \\
\hline $\begin{array}{l}\text { The "other costs" section in } \\
\text { pharmacoeconomic guidelines should be } \\
\text { clarified. }\end{array}$ & $\begin{array}{l}\text { It is fundamental to clarify which costs should be included in this section as the } \\
\text { inclusion/exclusion of specific cost elements (e.g., patient out-of-pocket } \\
\text { expenses) may impact cost-effectiveness assessment and access for patients. } \\
\text { Clarifying what is the impact of these costs in decision-making regarding health } \\
\text { technologies' funding is critical. }\end{array}$ \\
\hline
\end{tabular}

PRO are a valuable input in pharmaceutical reassessments.

Patient participation in the HTA process should be "transversal."

PRO are vital for pharmaceutical reassessments and should also be considered in the reimbursement process.

PRO collection will also depend on the creation of registries in order to properly collect relevant information.

Patients' point of view can be implemented along the process, with different representatives (e.g., patients, associations, informal caregivers for children/ mental illness, etc.).

There may be a biased outcome evaluation by patients (i.e., self-evaluation) and their representatives (e.g., patient associations)

Some patients are not able to answer basic questions for some current assessments - more complexity would even be worse.

Moderate level of agreement

In some cases, economic assessments could be The standard HTA model can be applied for cell and gene therapies, and there foregone (e.g., only perform a budget impact are no additional technical challenges (nonconsensual).

analysis for "niche" markets such as cell and Nonetheless, is it worth performing economic assessments for therapies usually gene therapies). targeting small population groups, or could a simple budget impact analysis be performed?

Outcome-based agreements may be a useful MEA such as outcome-based agreements may be an important mechanism to mechanism, especially for facilitating patients' ensure quicker and broader patient access to certain medicines. access to certain medicines.

However, these agreements may not be suitable for "general use" medicines (e.g., only for "niche" markets or some hospital therapies mostly used in small populations/with limited usage), since implementation difficulties can surpass their benefits.

Above all, robust registries are critical to support outcome-based agreements.

MIP may be applied in some cases, i.e., whenever there are medicines with variable value for different indications.

MIP may be a useful mechanism to apply whenever there is a significant difference in outcomes for distinct indications (based on independent assessments for each indication, i.e., with different comparators, treatment cost, etc.).

Despite this, MIP may be applicable in some cases; off-label usage and difficulties in assuring prescription tracking can be a serious challenge and hinder its implementation.

Interoperability between current (and future) Interoperability between systems and current/future registries is critical for registries and systems is critical and should be registries to function properly and to develop a national-level registry database. improved in the mid-term. Nevertheless, the capacity for improving the interoperability of systems and registries in the mid-term is not consensual, mostly due to the lack of qualified resources allocated to this purpose

Low level of agreement

Outcomes-based agreements could be Although it may be especially useful and applicable to medicines targeting small performed directly with hospitals (or hospital populations (e.g., gene or cell therapies) or "niche" markets, most stakeholders clusters) instead of being established with INFARMED. believe that the implementation difficulty would be too high for achieving the expected benefits of applying this approach.

Moreover, establishing these agreements with a single entity (i.e., INFARMED) may already be challenging, and thus the complexity of having more entities (i.e., hospitals or hospital clusters) directly negotiating these agreements with the pharmaceutical industry could hamper the benefits to be achieved by each party involved. 
weights). Additionally, they suggest that the reasons for approval by the authorities must be clearly stated. The need to create a tailored HTA process for medical devices was one of the top HTA-wise priorities highlighted by interviewees.

Patients' Participation. Although it is not clear what the best stage of the HTA process is to include the point of view of patients, it was agreed that their participation should be encouraged at the PICO and clinical assessment phases. A lower consent was reached regarding the participation of patients at other stages of the HTA process. This requires the definition of representativeness criteria and the development of proper tools and methodologies to capture and/or quantify PRO.

New Therapeutic Alternatives. New therapeutic alternatives present great uncertainty regarding therapeutic and economic outcomes. This could be addressed through the design of a national registry for usage and monitoring of health technologies. This registry should include hospital-based and population-based information that would permit evaluation of innovative technologies. Increasing international collaboration and information sharing was considered crucial for assessing new therapies, mostly due to their often small target populations.

How Can We Assess Therapies' Effectiveness in Portugal? The experts identified the need for a national strategy for registries. Current registries (e.g., Registo Oncológico Nacional [RON], ReumaPT, and SI.VIDA) must be improved and integrated, with a clear and transparent governance (e.g., regarding ownership and access). With regard to reassessments, they are dependent on the definition of clear criteria, timings, and outcomes to be measured.

Are We Ready for New Financial and Outcome-Based Agreements? Stakeholders referred that Portugal might not be fully prepared to implement new outcome-based agreements. However, MEA with outcome-based payments could be feasible to implement at the hospital level, with distinct clinical outcomes.

There was a relatively low consensus regarding MIP. Some participants referred that, despite comprising multiple challenges (e.g., prescription tracking, access, and ethical concerns), it may be viable in cases where the same drug has a significantly different value (outcomes) in distinct indications.

There was a low level of agreement regarding the possibility of establishing outcome-based agreements performed directly with hospitals (or hospital clusters) instead of being established with INFARMED. Although it may be especially useful and applicable to medicines tar- geting small populations, most stakeholders believe that the implementation would be quite difficult; moreover, establishing these agreements with more than 1 entity might add complexity to the process.

This final topic in the expert workshop had a significant degree of overlap with the young professionals' discussion on MEA and MIP. It is noticeable that the young professionals' insights were significantly aligned with HTA Portuguese experts' point of view, with no major point of disagreement or disruption between them.

\section{Discussion}

The research reported here aimed to review international experiences and establish a consensus based on expert opinion regarding future challenges in HTA and access of patients to new therapeutic alternatives in Portugal. The research comprised 3 phases, i.e., (1) mapping and evaluation of different HTA frameworks across Europe, (2) conduction of in-depth interviews of relevant stakeholders, and (3) development of 2 workshops for young professionals and relevant stakeholders.

Results for the review on the European frameworks showed that the purpose and sophistication of HTA frameworks varies across jurisdictions. For example, the level of economic evidence required is not the same in all countries, and reimbursement agreements also vary considerably. Despite most interviewees agreeing that the current HTA process design in Portugal is state of the art compared to other European countries, the recent change from a societal to an NHS perspective in Portuguese pharmacoeconomic guidelines was not seen as positive. It was acknowledged, however, that the societal perspective presents some methodological challenges.

All of the stakeholders agreed that having patients' point of view in the HTA process is crucial and provides added value. However, leveraging PRO comprises some challenges, especially regarding data gathering and monitoring. The need to create a tailored HTA process for medical devices was one of the top HTA priorities highlighted by the interviewees. Drug reassessments should be mandatory, despite the need for real-world evidence, and required data gathering may entail a significant challenge. The applicability of MEA and alternative pricing strategies gathered moderate agreement across the interviewees. MIP might be a useful resource, but its implementation is quite difficult due to prescription tracking needs and ethical concerns about patient discrimination. The requirement for the assessment of drug combina-
Port J Public Health 2021;39:36-47 DOI: $10.1159 / 000516501$
Pereira/Alves/Rodrigues/Caetano/BritoCruz/Sousa/Barata 
tions might present several challenges, i.e., when more than 1 company is involved.

The added value of a drug will be dependent on various criteria included in pharmacoeconomic evaluations (among them study perspective and the chosen comparator), and this will impact the reimbursement decision. The change in Portuguese guidelines contributed to an apparent divergence with European HTA frameworks. However, it is acknowledged that difficulties arise in harmonization of HTA across Europe, given country heterogeneity with respect to healthcare budgets and standards of care.

Most interviewees identified the inexistence of adequate registries and national level registries as a barrier to improved HTA. The development of registries and the generation of real-world evidence can be achieved by working with clinicians, patients, and regulators. Information systems based on electronic health records, as well as information and communication technologies, can provide a means to overcome the administrative costs associated with MEA and MIP. It is vital to create a national level registry, aggregating all of the data required for supporting pharmacoeconomic assessments. Intercommunication between systems and hospital level registries is fundamental to allow evidence-based decision making.

Although there have been frequent discussions in scientific and professional meetings regarding the future of HTA in Portugal, we were unable to find published studies that used qualitative methods to uncover stakeholder opinions regarding the problem at hand. There are, however, recent international examples of this broad line of research.

Kristensen et al. [28] reported the work of an ISPOR (International Society for Health Economics and Outcomes Research) HTA Council Working Group to provide guidance on good practices in the use of evidence to inform population-based healthcare decision-making for pharmaceuticals and other health technologies. They drew on literature reviews and expert opinions and concluded that, although many good practices have been developed, there are also areas where good practices are lacking, i.e., in defining the organizational aspects of HTA, the use of deliberative processes, and measurement of the impact of HTA.

O'Rourke et al. [29] reported on a survey of members of INAHTA (International Network of Agencies for Health Technology Assessment - a network of 50 publicly funded HTA agencies). The survey was aimed at gathering perspectives from agency leadership on the most important issues in HTA today. Among the top 10 challenges identified were the need to design better approaches to stakeholder involvement, the pressure to evolve existing HTA methods and processes, the scarcity of human resources to conduct HTA, and the inadequacy of data management systems and having no centralized database across public healthcare institutions. Overall, these findings are in accordance with those reported in the current paper and show that the challenges faced in Portugal are similar to those faced in other countries, thereby suggesting that much can be learned from an international experience.

Trowman et al. [30] summarized the discussions at the HTAi (Health Technology Assessment International) Global Policy Forum meetings over the last 2 years by pointing to key issues perceived by senior HTA users and producers. Among the issues discussed were internal and external stakeholder involvement in HTA processes, with the former comprising the HTA workforce, patients, and clinicians and the latter the general public, regulatory agencies, and the judiciary. Other key issues were globalization of HTA, transferability and harmonization, the use of real-world evidence and other data issues, affordability, and rapid indication change/expansions of new technologies. Once again, this article shows that much can be gained by being alert to how international agencies are handling current and future challenges.

Our study has several limitations. First, the workshops and the interviews were based on an interview topic guide that might be subject to bias. However, this potential bias was minimized since an initial effort was made to review the literature and finding current hot discussion topics in HTA across European countries. This allows for minimization of the bias in opinion gathering. A second limitation is that we focused mainly on economic topics, including economic evaluation and pricing and contractual mechanisms, rather than encompassing the full range of HTA approaches, particularly clinical, epidemiologic, and ethical questions. Third, in hindsight, our 2 workshops only considered 1 overlapping topic, i.e., MEA and MIP. As it turned out, there was considerable agreement in the opinions of young professionals and established experts. Future research might consider a greater degree of overlap in topics in order to contrast the 2 perspectives. Finally, it is acknowledged that our results suffer from a lack of generalizability. In-depth interviews and workshops were conducted in small groups chosen from relevant stakeholders, and random sampling methods were not used. Nevertheless, the interviewees and workshop participants were selected from different representative sectors, given their important role in the HTA process in 
Portugal, in the present or in the recent past, and thus their input and expertise is of great relevance.

This study also has some strengths. Our approach was to develop different depths of analysis, beginning with a review of the literature apropos European HTA frameworks and then moving on to in-depth interviews of relevant stakeholders and, finally, discussion of the results in 2 different workshops bringing together participants with different levels of expertise - on the one hand the viewpoints of relevant stakeholders, who represent the core of HTA in Portugal, and on the other the opinion of younger professionals, who might bring a degree of novelty and innovation to HTA discussions.

The most interesting aspect of this study is the use of qualitative methods to gather expert opinions. Despite being commonly used in the health arena, it is surprising how little such methods have been applied in HTA discussions. Qualitative methods allow the detailed exploration of issues, particularly in relation to complex phenomena about which informants may have deeply held beliefs, and they are particularly useful where the concern is to understand the views expressed $[11,31,32]$. The indepth interviews carried out provided detailed information that could not be reasonably obtained with other methods. Interviewing is particularly useful for understanding factors underlying particular beliefs and motivations behind behavior, decision-making, and the context for particular occurrences $[11,31,32]$. The 2 workshops, carried out in a structured manner, provided the ability to access professionally contextualized information and to ascertain shared knowledge and values. The opportunity for discussion allowed for confrontation of different perspectives and promotion of logical consensus. Our approach is akin to an extended focus group [12]. Focus groups, in the extended form of a workshop, are helpful in identifying the thinking, perceptions, and impressions of a particular group. They can yield a great deal of informative data but which are not readily generalizable [13]. It would be useful if future research took our approach further to better understand and prepare for future challenges in HTA and decision-making.

In conclusion, our study shows that the Portuguese HTA framework might be further adapted to upcoming challenges and evolve to improve access to innovative therapies. There is still a long path to follow towards convergence of HTA frameworks across Europe, but practitioners and decision makers can better adapt to change by drawing on international experience and listening to informed opinions of other stakeholders in the HTA process. DOI: $10.1159 / 000516501$

\section{Acknowledgement}

The authors wish to thank the following persons who participated in the interviews and workshops: Ana Lopes Vieira, Ana Paula Martins, António Melo Gouveia, António Rodrigues, Bruno Macedo, Carla Magalhães, Céu Mateus, Edgar Mascarenhas, Francisco Ramos, Francisco Rocha Gonçalves, Heitor Costa, Hélder Mota Filipe, Inês Teixeira, João Mendes, Klára Dimitrovová, Lara Ferreira, Margarida Rosa, Maria João Costa Lobão, Miguel Faria, Mónica Oliveira, Raquel Chantre, Rodrigo Murteira, Sílvia Miguel, Sofia André, Sofia Ferreira, Sónia Romano, Susana Santos, and Victoria Soares. The authors also wish to thank 2 anonymous referees who contributed to clarification of the initial version of this work.

\section{Statement of Ethics}

Ethical approval was not required due to the nature of this study. All of the interviewees and workshop participants were fully informed about the content of this study and gave verbal and written consent for participation beforehand. The voluntary and confidential nature of participation was stressed, and the participants had the right to withdraw from this study at any time.

\section{Conflict of Interest Statement}

B.R. and B.B. are employees of Janssen-Cilag Farmacêutica. J.A. is a member of CATS - the Commission for Evaluation of Health Technologies, Infarmed.

\section{Funding Sources}

This study was funded by Janssen-Cilag Farmacêutica. The NOVA National School of Public Health received an unrestricted grant to design, develop, and carry out this study. The funding source had no institutional role in the study design and execution or interpretation of the results.

\section{References}

Pereira/Alves/Rodrigues/Caetano/BritoCruz/Sousa/Barata
1 European Commission. Innovative payment models for high-cost innovative medicines: report of the Expert Panel on Effective Ways of Investing in Health (EXPH). Luxembourg: Publications Office of the European Union; 2018.

2 Sorenson C, Drummond M, Bhuiyan-Khan B. Medical technology as a key driver of rising health expenditure: disentangling the relationship. Clinicoecon Outcomes Res. 2013 May;5:223-34.

3 World Health Organization. WHO | HTA definitions [Internet]. Geneva: WHO; 2015 [cited 2020 Jan 17]. Available from: https:// www.who.int/health-technology-assessment/about/Defining/en/. 
4 Organisation for Economic Co-Operation and Development. Value for money in health spending. Paris: OECD; 2010.

5 Pereira J, Barbosa C. Avaliação económica aplicada aos medicamentos. In: Pereira J, editor. Farmacoeconomia: princípios e métodos. Madrid: Wolters Kluwer; 2009.

6 Garrido VM, Kristensen FB, Camilla Palmhøj $\mathrm{N}$, Busse R. Health technology assessment and health policy-making in Europe: current status, challenges and potential. Copenhagen: European Observatory on Health Systems and Policies; 2008.

7 Akehurst RL, Abadie E, Renaudin N, Sarkozy F. Variation in health technology assessment and reimbursement processes in Europe. Value Health. 2017 Jan;20(1):67-76.

8 Silva E, Pinto G, Sampaio C, Pereira J, Drummond M, Trindade R. Orientações metodológicas para estudos de avaliação económica de medicamentos. Lisbon: Infarmed; 1998.

9 Pereira JA. Revisão das orientações metodológicas de estudos de avaliação económica de medicamentos em Portugal. Port J Public Health. 2018;36(1):I-IV.

10 Perelman J, Soares M, Mateus C, Duarte A, Faria R, Ferreira L, et al. Orientações metodológicas para estudos de avaliação económica. Lisboa: INFARMED - Autoridade Nacional do Medicamento e Produtos de Saúde; 2019.

11 Pope C, Mays N, editors. Qualitative research in health care. London: Blackwell; 2006.

12 Timotijevic L, Raats MM. Evaluation of two methods of deliberative participation of older people in food-policy development. Health Policy. 2007 Aug;82(3):302-19.

13 Brown J. Interviews, focus groups, and Delphi techniques. In: Brough P, editor. Advanced research methods for applied psychology. New York: Routledge; 2019. pp. 95-106.
14 Angelis A, Lange A, Kanavos P. Using health technology assessment to assess the value of new medicines: results of a systematic review and expert consultation across eight European countries. Eur J Health Econ. 2018 Jan;19(1):123-52.

15 Sorenson C. The role of HTA in coverage and pricing decisions: a cross-country comparison. Euro Obs. 2009;11(1):1-4.

16 Allen N, Liberti L, Walker SR, Salek S. A comparison of reimbursement recommendations by European HTA agencies: is there opportunity for further alignment? Front Pharmacol. 2017 Jun;8:384.

17 National Institute for Clinical Excellence. Guide to the methods of technology appraisal. London: NICE; 2013.

18 Flume M, Bardou M, Capri S, Sola-Morales O, Cunningham D, Levin LA, et al. Approaches to manage 'affordability' of high budget impact medicines in key EU countries. J Mark Access Health Policy. 2018 Jun;6(1):1478539.

19 IQVIA. Pharmaceutical pricing \& reimbursement concise guide: France. Durham: IQVIA; 2018.

20 IQVIA. Pharmaceutical pricing \& reimbursement concise guide: The Netherlands. Durham: IQVIA; 2018

21 IQVIA. Pharmaceutical pricing \& reimbursement concise guide: Belgium. Durham: IQVIA; 2018.

22 IQVIA. Pharmaceutical pricing \& reimbursement concise guide: Italy. Durham: IQVIA; 2018.

23 IQVIA. Pharmaceutical pricing \& reimbursement concise guide: United Kingdom. Durham: IQVIA; 2018.

24 IQVIA. Pharmaceutical pricing \& reimbursement concise guide: Spain. Durham: IQVIA; 2018
25 IQVIA. Pharmaceutical pricing \& reimbursement concise guide: Portugal. Durham: IQVIA; 2018

26 Neri M, Towse A, Garau M. Value assessment of multi-indication pricing (MIP): practical solutions and steps to move forward - OHE briefing. London: Office of Health Economics; 2018.

27 Marsden G, Towse A, Pearson SD, Dreitlein B, Henshall C. Gene therapy: understanding the science, assessing the evidence, and paying for value: a report from the 2016 ICER Membership Policy Summit. London: ICER Membership Policy Summit; 2017.

28 Kristensen FB, Husereau D, Huić M, Drummond $\mathrm{M}$, Berger ML, Bond $\mathrm{K}$, et al. Identifying the need for good practices in health technology assessment: summary of the ISPOR HTA Council Working Group Report on Good Practices in HTA. Value Health. 2019 Jan;22(1):13-20.

29 O’Rourke B, Werkö SS, Merlin T, Huang LY, Schuller T. The 'top 10' challenges for health technology assessment: INAHTA viewpoint. Int $\mathrm{J}$ Technol Assess Health Care. 2020;36(1):1-4.

30 Trowman R, Ollendorf DA, Sampietro-Colom L. Burning Issues in health technology assessment and policy making: what's keeping senior health technology assessment users and producers up at night? Int J Technol Assess Health Care. 2020;36(1):5-7.

31 Coast J. Qualitative methods for health economics. London: Rowman \& Littlefield International; 2017.

32 Owen-Smith A, Coat J. Understanding data collection: interviews, focus groups and observation. In: Coast J, editor. Qualitative methods for health economics. London: Rowman \& Littlefield International; 2017. 